Forrestall in "The Shamrock Tradition" (Irish Ecclesiastical Record, 36, 63, 1930, Dublin).

As to which species of clover is the shamrock, the overwhelming majority of the Irish consider the small yellow-flowering trefoil as the shamrock. This usage of the people of Ireland has the force of a living tradition and outweighs the evidence of some of the dictionaries and lexicons which refer the shamrock to Trifolium repens, the white or Dutch clover. Botanical names, unless used by systematic botanists, are often misapplied. The plant meant by the people of Ireland has much greater claim to accuracy than a botanical name in a dictionary. Mgr. Patrick Nolan, Lakeland, Florida, recalls that as a boy in Belfast he learned to distinguish the shamrock from the clover (T. repens) by the white spots commonly shown on the leaves of the latter. T. dubium does not have white-spotted leaves.

To sum up : the shamrock of Irish and Scotch Gaelic language and literature and tradition is a clover, in the living tradition of the Irish, Trifolium dubium Sibth. The shamrock of English writers is the wood-sorrel.

\section{NEW CROP VARIETIES}

$\mathrm{N}^{\mathrm{BV}}$

EW introductions from Sweden, Denmark, Holland, France, Canada and the United States are included among the 163 distinct varieties and strains of crop plants now being tested by the National Institute of Agricultural Botany, Cambridge. Many very promising varieties have been submitted by private and 'official' plant breeders working in England, Wales, Scotland and Northern Ireland. In order to give the varieties every opportunity of demonstrating their merits, the fifteen principal yield trials are repeated at centres as far apart as Newcastle-on-Tyne, Bridgwater, and Wye (Kent).

To secure accurate yield results the Institute normally includes each variety in eight different plots, while seasonal effects are overcome by continuing the trials for three seasons in succession. Among the 98 varieties included in special observation plots are fourteen French varieties of wheat submitted by the Syndicat des Producteurs de Semences Selectionnées which are growing alongside the well-known variety Bersee.

Resistance to attacks of such diseases as yellow rust and loose smut, as well as 'lodging' of the straw in cereals, are carefully watched, and the most successful varieties will be promoted from observation plots to yield trials in 1947.

The quality of the resulting crop is carefully studied in co-operation with interested authorities such as the Cereals Research Station at St. Albans, and the Institute of Brewing. The progress made in the breeding of higher quality varieties of oats, wheat, barley, potatoes and sugar beet, etc., is largely the result of careful testing of older varieties in past years.

Apart from the headquarters trial ground at Cam. bridge, three of the pre-war testing stations are now in full progress at the Harper Adams College (Shropshire), Cannington Farm Institute (Somerset), and the Norfolk Agricultural Station at Sprowston. New regional stations have been established with the approval of the Ministry of Agriculture at the following centres: King's College Farm, Nafferton, Newcastle-on-Tyne; Midland Agricultural College
Farm, Loughborough; Hampshire Farm Institute at Sparsholt; and the South-Eastern Agricultural College at Wye. In Yorkshire, trials have been distributed between the Askham Bryan Farm Institute and selected farms in the Wolds and Holderness districts of East Riding.

Combine harvesters will be used to harvest many of the trials in Cambridge, Norfolk and Yorkshire. The 'Combine' enables additional trials to be conducted on farms possessing soil or climatic conditions which are of special interest but which are situated at some distance from a testing station.

The following members of staff have recently been appointed to the National Institute of Agricultural Botany : Mr. J. C. Cullen, senior scientific officer in charge of potato trials and propagations; Dr. F. Earnshaw, economic botanist; and Messrs. P. J. Jones, A. F. Kelly, G. W. Mann, L. A. Willey, A. Main, G. G. Graham, J. D. Ivins and J. Munro, crop recorders at the trial centres.

\section{EXPLORING MAGNETIC FIELDS}

A $\mathrm{N}$ article by Lillian Shapiro (Bell Lab. Rec., 23, No. 8; August 1945) describes means and methods devised for exploring the magnetic fields employed for guiding the electron stream in a cathode ray tube. Search coils are used in the method and a special winding machine and technique were developed to produce them.

Two coils with the axis of one at right angles to that of the other are wound on a common mandrel, and this assembly, with an outside diameter of about 0.2 in., is slipped into the end of a very thin-walled plastic search tube in such a way that one of the coils is concentric with the tube. As this search tube is moved along the axis of the tube, this latter coil will always be in a position to measure the component of the flux along the $z$-axis, while the other coil may be used to measure the components along the other two axes, turning the tube first so that the coil is perpendicular to the $x$-axis and then turning it $90^{\circ}$ to bring it perpendicular to the $y$-axis.

Since such a search tube cannot actually be inserted in a cathode ray tube, exactly equivalent conditions are simulated by using a solid plastic cylinder with an outside diameter the same as the cylindrical section of the cathode ray tube. This plastic cylinder is accurately drilled longitudinally with twenty-one holes. It is then slipped inside the deflexion assembly of the cathode ray tube just as the tube itself would be. The magnetic fields set up in the plastic cylinder are thus exactly the same as those in a cathode ray tube when the same deflexion assembly is used.

The search tube carrying the exploring coils is inserted successively in the twenty-one holes of the cylinder, and a number of readings is taken in each so as to record the field at successive positions along the length of the tube. At each position, a reading on the coil that is concentric with the tube gives the $z$ component of the field. Readings of the $x$ - and $y$-components are made with the transverse coil, which may be rotated to any desired position merely by turning the tube. On the end of the tube remote from the exploring coils, there is a protractor from which the $x$ - and $y$-axes may be determined.

One of the holes in the plastic block is exactly down the centre. The maximum field in this hole is usually rectilinear, with a component along one axis 